Article

\title{
Petrographic and Mechanical Characteristics of Concrete Produced by Different Type of Recycled Materials
}

\author{
Petros Petrounias $^{1, *(\mathbb{D})}$, Panagiota P. Giannakopoulou ${ }^{1}\left(\mathbb{D}\right.$, Aikaterini Rogkala ${ }^{1}(\mathbb{D}$, \\ Paraskevi Lampropoulou ${ }^{1}$, Basilios Tsikouras $\left.{ }^{2}{ }^{(}\right)$, Ioannis Rigopoulos ${ }^{3}{ }^{\circledR}$ and \\ Konstantin Hatzipanagiotou ${ }^{1}$ \\ 1 Section of Earth Materials, Department of Geology, University of Patras, 26504 Patras, Greece; \\ peny_giannakopoulou@windowslive.com (P.P.G.); krogkala@upatras.gr (A.R.); \\ p.lampropoulou@upatras.gr (P.L.); k.hatzipanagiotou@upatras.gr (K.H.) \\ 2 Physical and Geological Sciences, Faculty of Science, Universiti Brunei Darussalam, Jalan Tungku Link, \\ Gadong BE1410, Bandar Seri Begawan, Brunei Darussalam; basilios.tsikouras@ubd.edu.bn \\ 3 Department of Civil and Environmental Engineering, University of Cyprus, 1678 Nicosia, Cyprus; \\ rigopoulos.ioannis@ucy.ac.cy \\ * Correspondence: Geo.plan@outlook.com; Tel.: +30-2610996288
}

Received: 2 April 2019; Accepted: 17 June 2019; Published: 19 June 2019

\begin{abstract}
This paper examined three different types of recycled materials, such as beer green glass, waste tile, and asphalt, which will be used in different mixtures in order to prepare concrete specimens and, more specifically, their effect on concrete strength and how the petrographic characteristics of various recycled materials influenced the durability of C25/30 strength class concrete. Particular emphasis was placed on the effect of artificial microroughness of glassy and smooth surfaces of recycled materials on their final concrete strength. The concrete strength values do not show great variance, but their limited differences have been qualitatively interpreted by a new promising petrographic methodology, including the study of the surface texture of the used aggregate materials. Concretes are produced with constant volume proportions, workability, mixing, and curing conditions while using different sizes of each aggregate type. The aggregates were mixed both in dry and water saturated states in concretes. Concretes that are made by a mixture of beer green glass with quartz primer, as well as of tile with quartz primer, presented the optimum possible results of the compressive strength.
\end{abstract}

Keywords: petrographic characteristics; recycled materials; concrete petrography; quartz primer

\section{Introduction}

Concrete, a mixture of cement, aggregates, and water, is the most used man-made material and it has numerous civil engineering applications, including roads, bridges, and dams [1-4]. The basic component of concrete is the material that binds the aggregate particles together, commonly comprising a mixture of cement and water $[1,5,6]$. Concrete structures can be described as a three-phase system that is composed by hardened cement paste, aggregate, and the interface between aggregate particles and cement paste $[7,8]$. Several researchers have studied the effect of various additives, such as fly ash, low calcium fly ash, coal fly ash, $\mathrm{ZnO}$ nanoparticles, carbon nano tubes, and polypropylene fibers on the quality of the cement and on the physical and on the mechanical characteristics of concretes [9-14]. More specifically, the use of fly ash in $20 \%$ in the cement of concrete specimens enhances the durability of the produced concretes, as small microcracks have been observed in the interfacial transition zone [11]. Additionally, the use of low calcium fly (in percentage less than 30\%) 
in the cement positively contributes to their compressive strength [10]. However, aggregates are the major constituents of concrete, typically occupying between $70 \%$ and $80 \%$ of its volume.

However, the rapid growth of the construction industry has led to environmental problems that are caused by excessive mining and the use of natural resources, such as aggregate and cements [15]. Approximately 275 million tons of new aggregate are annually extracted in the United Kingdom (UK) and this is estimated to be increased by $1 \%$ each year [16]. Concern over the damage to the surrounding environment, destruction of the ecological balance, and emission of greenhouse gases have become increasingly important [17]. In addition, the improper waste recycling and the huge number of industrial by-products have caused serious environmental pollution $[18,19]$. Therefore, there is a need to improve the reuse value of waste materials. A variety of waste materials have been recycled and used as aggregate in concrete blocks since the usage of conventional aggregates is not environmental friendly and causes depletion of natural resources [20].

Different recycled waste materials have been used for the production of concrete, such as: clay [21], fly ash [22,23], waste glass [24-28], crushed bricks [28-31], cathode ray tube glass waste [28,32,33], crumb rubber waste [28], ceramic and tile industry waste [28,34-36], and plastic waste [28,37-39].

Several studies have been carried out to examine the impact of use of glass waste in the produced concrete behaviour, noticing that the content of glass waste influences as the concrete strength as well as its workability $[24,40]$.

In general, glass is a highly transparent material that is formed by melting a mixture of materials, such as soda ash and $\mathrm{CaCO}_{3}$ at high temperatures, followed by cooling, during which solidification occurs without crystallization. Glass is widely used through manufactured products, such as sheet glass, bottles, glassware, and vacuum tubing. Waste glass became a main issue for districts all over the world due to the changes in the environmental laws, so it could be of significant encouragement to use the waste glass in different construction applications, such as concrete. More specifically, a glass cullet is used in the construction industry, a material that is produced from recycling glass that is a result of breakage [41,42]. Many efforts have been conducted to use glass cullet into concrete applications. In the past, many researchers investigated the waste glass cullet without adequate interpretation. In recent years, scientific development and changes in environmental laws have encouraged the use of glass cullet as one or more components of concrete. Cullet is used in concrete in three different types: as a coarse aggregate, as a fine aggregate (sand), and in a powdered form (mineral antimixture) [43,44]. A number of scientists have used waste glass cullet in concretes, partially replacing natural aggregates, examining how the different proportions of the waste glass cullet influence on the produced concrete properties $[24,25,28,40,43,45-47]$. The alkali-silica reaction (ASR) in concrete containing crushed glass aggregate has also received research attention since crushed glass is rich in silica [47-49]. Several researchers have reported that the particle size of the glass waste plays vital role in the ASR destructive reaction and the performance of concrete [27]. The recycling of these wastes will aid in conserving the earth's natural resources, minimizing the landfill spaces and saving energy and money [50].

Moreover, the use of recycled ceramic tile waste as aggregate in concrete also contributes to relieving industrial waste disposal problems and simultaneously in maintaining natural aggregate resources [51]. Several researchers have attempted the partial or total substitution of fine and coarse natural aggregates $[28,52-54]$, examining the produced concrete properties, while mainly taking advantage of the special properties of tile waste particles.

Crushed asphalt, which is a typical by-product in the field of asphalt road rehabilitation, is also used for the partial replacement of natural aggregates in concrete, contributing to the reduction of the waste storage, which has dramatically increased during the last years [55].

In concrete, the most observed faults, either in the case of waste glasses or in the cases of asphalt and tiles, are due to their smooth surfaces [26,28], which are responsible for the extended cracks and detachments along the rims of the aggregate particles with the cement paste, limiting the final concrete strength [56]. 
The goal of this paper is to highlight the effect of microroughness of the recycled waste materials that are used as aggregates on the bonding quality and on the mechanical characteristics of the produced concretes. The general scope of this paper is the increase of the recycled waste materials use in construction engineering processes following the basic concept of the cyclic economy.

\section{Materials and Methods}

\subsection{Materials}

Three different types of recycled materials, such as beer green glasses, waste tiles from renovations, and asphalt, were used in different mixtures (Table 1) for preparing concrete specimens. Normal Portland cement (CEM II 32.5N), which was conformed according to EN 197-1 [57], was used with the recycled materials that were used as aggregates for the production of concrete. Potable tap water, free of impurities, such as salt, silt, clay, and organic matter, was used for mixing and curing the concrete. The $\mathrm{pH}$ value of water was 7.0. In order to keep a consistent composition for all of the concrete specimens, we adopted the principle of maintaining the same volume of aggregate per $1 \mathrm{~m}^{3}$ of the mixture. The proportions of the concrete mixtures, by mass, were $1 / 6 / 0.63$ cement, aggregate, and water ratio.

\subsection{Methods}

The surface texture of the recycled materials was studied by using Secondary Electron Images (SEI), according to BS 812 Part 1 [58], which outlines six qualitative categories, i.e., glassy, smooth, granular, rough, crystalline, honeycomb, and porous. An artificial increase of microroughness of the recycled materials specimens was carried out, since the microroughness of materials used as aggregates in concretes plays severe role on their final strength, as it is responsible for the adequate bonding between the cement paste and the aggregate particle. In this study, the artificial increase of the microroughness of the recycled materials was carried out by coating them with quartz primer three times in total, one every $24 \mathrm{~h}$ (Figure 1b,d). The choice of using a quartz primer to artificially increase the aggregate microroughness is because the quartz primer is a product, which, although scientifically not used for this purpose, is commercially widely used to increase the low-adhesion surfaces, such as tiles and marbles. Sixteen normal concrete cube specimens $(150 \times 150 \mathrm{~mm})$ were made from the eight different mixtures containing recycled materials (Table 1), according to ACI-211.1-91 [59] by using a concrete mixer (C166-02, Pan Type, Forced Speed). All of the parameters remained constant in all the concrete specimens. The recycled materials were crushed through standard sieves and then separated into the size classes of 2.00-4.75, 4.45-9.5, and 9.5-19.1 mm, and then washed before their used in concrete specimens. After $24 \mathrm{~h}$, the samples were removed from the mold and were cured in water for 28 days. The curing temperature was $20 \pm 3^{\circ} \mathrm{C}$. These specimens (two cubes for each concrete) were tested in a compression testing machine with an increasing rate of load of $140 \mathrm{~kg} / \mathrm{cm}^{2}$ per minute. The division of the value of the load at the moment of failure over the area of specimen was used to calculate the compressive concrete strength. The compression test was elaborated according to BS EN 12390 [60] by using a C108N Digitec and C098N Autotec machine with accuracy of $\pm 5 \%$ of the indicated load. The quality cohesion between the cement paste and the aggregate particles in concretes were examined after the compressive strength test. For this reason, two concrete particles for each sample were studied in a polarizing microscope (Leica Microsystems Leitz Wetzlar, Germany), according to ASTM C856-17 [61], as well as in scanning electron microscope (JEOL JSM-6300 SEM) equipped with energy dispersive and wavelength spectrometers (EDS and WDS) and INCA software at the Laboratory of Electron Microscopy and Microanalysis, University of Patras. The operating conditions were accelerating voltage $25 \mathrm{kV}$ and beam current $3.3 \mathrm{nA}$, with a $4 \mu \mathrm{m}$ beam diameter. 

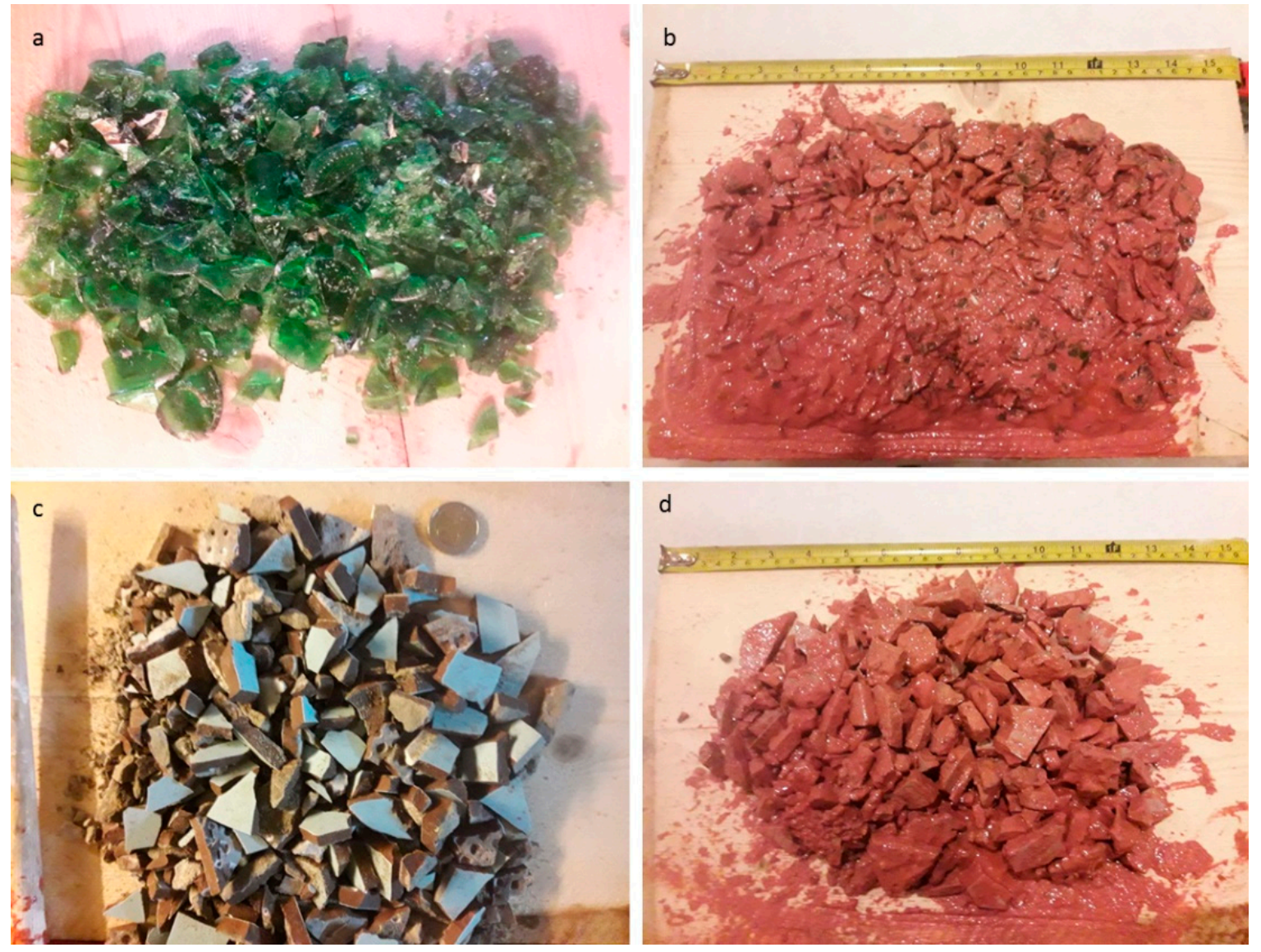

Figure 1. Photos showing recycled materials used as aggregate particles in various mixtures: (a) beer green glass; (b) beer green glass coated with quartz primer; (c) waste tiles; and, (d) waste tiles coated with quartz primer. 
Table 1. Mixtures of recycled materials used as aggregates in concretes $(X=$ contained recycled material and - = not used recycled material).

\begin{tabular}{|c|c|c|c|c|c|c|c|c|c|c|c|c|c|c|c|}
\hline \multirow[t]{2}{*}{ Sample } & \multicolumn{5}{|c|}{$2.00-4.75 \mathrm{~mm}$} & \multicolumn{5}{|c|}{$4.45-9.5 \mathrm{~mm}$} & \multicolumn{5}{|c|}{$9.5-19.1 \mathrm{~mm}$} \\
\hline & glass & $\begin{array}{l}\text { glass with } \\
\text { primer }\end{array}$ & tile & $\begin{array}{l}\text { tile with } \\
\text { primer }\end{array}$ & asphalt & glass & $\begin{array}{l}\text { glass with } \\
\text { primer }\end{array}$ & tile & $\begin{array}{l}\text { tile with } \\
\text { primer }\end{array}$ & asphalt & glass & $\begin{array}{l}\text { glass with } \\
\text { primer }\end{array}$ & tile & $\begin{array}{l}\text { tile with } \\
\text { primer }\end{array}$ & asphalt \\
\hline S1 & $X$ & - & - & - & - & $x$ & - & - & - & - & $X$ & - & - & - & - \\
\hline S2 & - & $x$ & - & - & - & - & $x$ & - & - & - & - & $X$ & - & - & - \\
\hline S3 & - & - & $x$ & - & - & - & - & $x$ & - & - & - & - & $x$ & - & - \\
\hline S4 & - & - & - & $x$ & - & - & - & - & $x$ & - & - & - & - & $x$ & - \\
\hline S5 & - & $x$ & - & - & - & - & - & - & - & $x$ & - & - & - & $x$ & - \\
\hline S6 & - & $x$ & - & - & - & - & - & - & $x$ & - & - & - & - & $x$ & - \\
\hline S7 & - & $x$ & - & - & - & - & $X$ & - & - & - & - & - & - & $X$ & - \\
\hline S8 & - & - & - & - & $x$ & - & - & - & - & $x$ & - & - & - & - & $X$ \\
\hline
\end{tabular}




\section{Results and Discussion}

\subsection{Test Results of Concrete}

\subsubsection{Surface Texture of the Recycled Materials}

The microroughness of the beer green glass, waste tile, and asphalt, as well as of the beer green glass with quartz primer and of the waste tile with quartz primer was examined. The beer green glass shows glassy surface, while the beer green glass with quartz primer shows almost smooth surfaces, as can be seen in Figure 2a (Figure 2b). The examined surface of the waste tile seems to be smooth (Figure 2c), while the waste tile with quartz primer shows more rough surfaces in contrast to those without primer (Figure 2d). Concerning the asphalt surface, it was observed that the calcite crystals contained contribute to surface, ranging from smooth to rough (partially porous) (Figure 2e). In general, the quartz primer, as a high adherence material, has given microroughness to the recycled materials that are used as aggregates in concrete specimens.
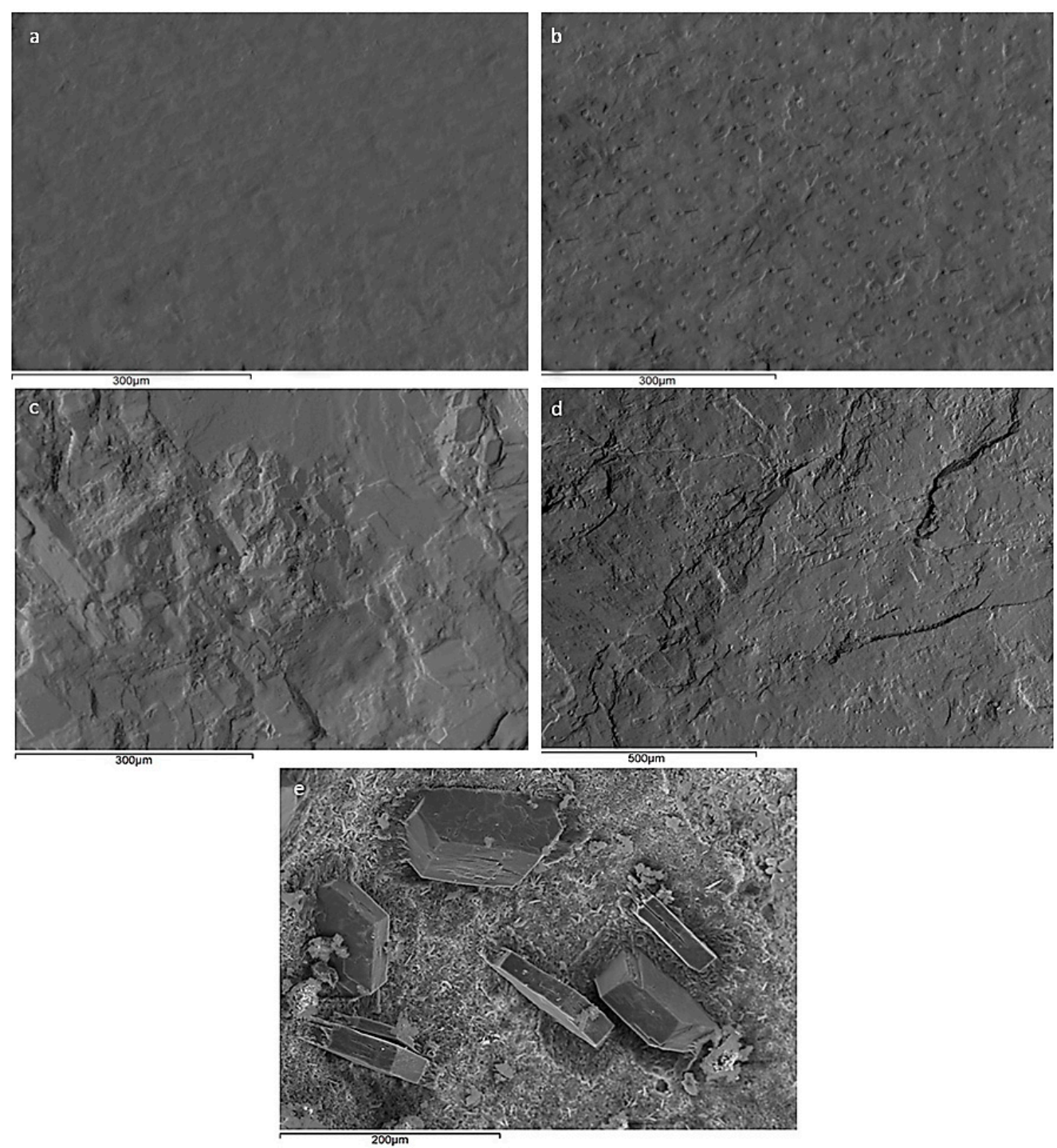

Figure 2. Secondary electron images (SEI) images showing the surface texture of representative recycled materials: (a) beer green glass; (b) beer green glass with quartz primer; (c) waste tile; (d) waste tile with quartz primer; and, (e) asphalt. 
This fact may mainly happen due to the characteristics of quartz grains that are contained in the primer. Quartz primer adheres through the synthetic resins to the surfaces of the recycled materials used as aggregates, hence presenting less cracks and detachments between the aggregate particles and the cement paste in concrete specimens. In general, the aggregate particle acts as a receptor for the cement paste around the aggregate and it also accepts the penetration of the cement paste during its initial maturity among the protrusive mineral phases. As a result, the cement paste, during its full maturity, has also acquired microroughness between the interface of the cement paste and aggregate particle. In general, several researchers, such as Rigopoulos et al. [62], have studied the effect of microroughness of various rocks and how it affects their quality as aggregates according to the BS 812 Part 1 [58]. More specifically, Petrounias et al. [56,63] who studied various rocks on their suitability as concrete aggregates reported that the microroughness of the aggregate particles plays a determinant role in the quality of the concrete products. Smooth surface constitute determinant negative factor for poor bonding of the aggregate grain and the cement paste and, hence, low concrete strength. However, Abdallah and Fan [26], as well as Meng et al. [28], who have studied different recycled materials as aggregates and their suitability in concrete specimens, referred that the smooth surfaces of these materials were responsible for extended cracks and detachments along the rims of the aggregate particles with the cement paste.

\subsubsection{Compressive Strength of the Concretes}

Table 2 lists the results from the compressive strength test of concrete specimens. The concrete strength ranged from 14 to $20 \mathrm{MPa}$ after 28 days of curing. The results of the compressive strength finally indicate concretes of different categories, such as C12/15 and C16/20 [64]. Even though there are small differences between the UCS values, these differences may classify the produced concretes in different applications. The lowest compressive strength values were observed in concrete specimens that were made by mixtures exclusively containing glass or asphalt as aggregates (sample S1 and S8, respectively). On the other hand, concretes that are made by mixtures of glass with a primer in the lowest size classes and tile with primer in the highest size classes present the highest compressive strength values. Moreover, concretes that were made with recycled materials coated with primer presented higher strength values than those of concretes that were made of the respective mixtures without primer coating (sample S6 and S7). The results of the compressive strength test of the concrete specimens are in accordance to the artificial given microroughness of the recycled materials that are used as aggregates in concretes. In general, the artificial increase of microroughness seems to positively contribute to all the strength values of the studied concrete specimens. 
Table 2. Type of the recycled materials used as aggregates in concrete specimens and their type of microroughness according to BS 812 Part 1 [58] standard as well as the compressive strength of concrete specimens of different mixtures of recycled materials (standardized value of compressive strength of concrete $\mathrm{C} 25 / 30$ according to EN 12390).

\begin{tabular}{|c|c|c|c|c|c|c|}
\hline Sample & $\begin{array}{c}\text { Recycled Materials Used as } \\
\text { Aggregates } \\
\text { Grain Sizes: }(2.00-4.75 / \\
4.45-9.5 / 9.5-19.1 \mathrm{~mm})\end{array}$ & $\begin{array}{l}\text { Petrographic Characteristics of the } \\
\text { Aggregates Microroughness }\end{array}$ & Microroughness & $\begin{array}{l}\text { Compressive } \\
\text { Strength of the } \\
\text { Concretes (Mpa) }\end{array}$ & $\begin{array}{l}\text { Compressive } \\
\text { Strength of the } \\
\text { Concretes (Mpa) }\end{array}$ & $\begin{array}{l}\text { Mean Value of the } \\
\text { Compressive } \\
\text { Strength of the } \\
\text { Concretes (Mpa) }\end{array}$ \\
\hline S1 & Glass/glass/glass & $\begin{array}{l}\text { Conchoidal fracture without projections of } \\
\text { microtopography }\end{array}$ & Glassy & 14.20 & 13.80 & 14.00 \\
\hline S2 & $\begin{array}{l}\text { Glass with primer/Glass with } \\
\text { primer/Glass with primer }\end{array}$ & Smooth due to fracture of laminated material & Smooth & 14.80 & 15.29 & 15.00 \\
\hline S3 & Tile/tile/tile & Smooth due to fracture of laminated material & Smooth & 16.90 & 17.10 & 17.00 \\
\hline S4 & $\begin{array}{l}\text { Tile with primer/Tile with } \\
\text { primer/Tile with primer }\end{array}$ & $\begin{array}{l}\text { Smooth due to fracture of laminated materials } \\
\text { with scares projections of microtopography }\end{array}$ & Smooth to rough & 17.30 & 17.60 & 17.50 \\
\hline S5 & $\begin{array}{l}\text { Asphalt/tile with primer/glass } \\
\text { with primer }\end{array}$ & $\begin{array}{l}\text { Smooth due to fracture of laminated materials } \\
\text { with scares projections of microtopography and } \\
\text { locally with presence of pores }\end{array}$ & $\begin{array}{l}\text { Smooth to rough } \\
\text { (partially porous) }\end{array}$ & 16.00 & 16.05 & 16.00 \\
\hline S6 & $\begin{array}{l}\text { Glass with primer/tile with } \\
\text { primer/tile with primer }\end{array}$ & $\begin{array}{l}\text { Rough fracture showing more or less uniform } \\
\text { rounded grains }\end{array}$ & Rough to granular & 19.85 & 20.20 & 20.00 \\
\hline S7 & $\begin{array}{l}\text { Glass with primer/Glass with } \\
\text { primer/tile with primer }\end{array}$ & $\begin{array}{l}\text { Rough fracture of fine or medium grained } \\
\text { material }\end{array}$ & Rough & 18.10 & 17.90 & 18.00 \\
\hline S8 & Asphalt & $\begin{array}{l}\text { Smooth due to fracture of laminated material } \\
\text { with scares projections of microtopography and } \\
\text { with presence of pores }\end{array}$ & $\begin{array}{l}\text { Smooth to rough } \\
\text { (partially porous) }\end{array}$ & 14.00 & 14.05 & 14.00 \\
\hline
\end{tabular}




\subsection{Petrographic Features of the Concretes}

Petrographic observation of the thin sections, as well as of the concrete particles using polarizing and scanning electron microscopes, was carried out. The careful microscopic observation of concrete specimens made by beer green glass in all size classes (Table 1) without quartz primer as aggregate (Figure 3a) revealed lower cohesion between the aggregate grains (beer green glass) and the cement paste, in contrast to those that were made by beer green glass coated with quartz primer in all size classes, (Figure 3b), due to their higher microroughness given after their coating with quartz primer. This microscopic observation is in accordance with their concrete strength values, as sample S1 presented lower values than sample S2, as well as with the artificially improved microroughness of the used recycled material used as aggregate (Table 2). Moreover, as shown in Figure 3b, the resined quartz primer had very good application on the glass grains, a fact that positively contributed to the strength of the produced concrete specimen. Additionally, the very good application of quartz primer is certified from its uniform distribution around the glass and from the smoother given surfaces (Figure 2b, Table 1). These results have been also verified through the observations of scanning electron microscopy (Figure 4a,b). Similar results have been observed after the application of quartz primer on tiles. The uniform distribution of the quartz primer around tile leads to increased concrete strength, in contrast to those specimens that were made without having been coated with quartz primer (sample S4 and S3, respectively). Concrete specimen made by tile, which mostly includes quartz particles and Fe-oxides, as aggregate without having been coated with quartz primer presents satisfactory strength values (sample S3, Table 2). Additionally, concrete specimens that were exclusively made by tile with quartz primer present satisfactory strength values (sample S4, Table 2) as the higher microroughness artificially given after their coating with quartz primer contribute to the good cohesion between the cement paste and the aggregate particles (sample S4). When tile was used as aggregate (in all size classes) in concrete, better cohesion between this and the cement paste was observed after its coating with quartz primer, due to its higher given microroughness (Figure $3 \mathrm{~d}$ ) than when the concrete specimens were made by tile without quartz primer as aggregate (Figure 3c). These results have been also verified through the observations of scanning electron microscopy (Figure 4c,d). However, in the case of using asphalt, as characterized by several calcite particles, as aggregate in concrete, coating with the quartz primer has not been used, since it was not considered to be necessary due to the already high microroughness, concrete of low strength have been produced. Although the cohesion between the asphalt and the cement paste is considered to be satisfactory (Figure 3e), the low strength of asphalt grains, combined with the impregnation of asphalt and cement paste in Fe-oxides may lead to failure of the material and the low strength of the produced concrete. Furthermore, in the case of mixture of recycled materials that are used as aggregates in concrete specimens, such as beer green glass and tile both coated with quartz primer, better cohesion between these materials and the cement paste was observed (Figure 3f), in contrast to their unique use in concretes after having been coated with quartz primer. Concrete specimens that were made by mixture of beer green glass with quartz primer, as well as of tile with quartz primer, present the highest strength values (sample S6 and S7, Table 2), as the bonding between these aggregates and the cement paste is strong. 

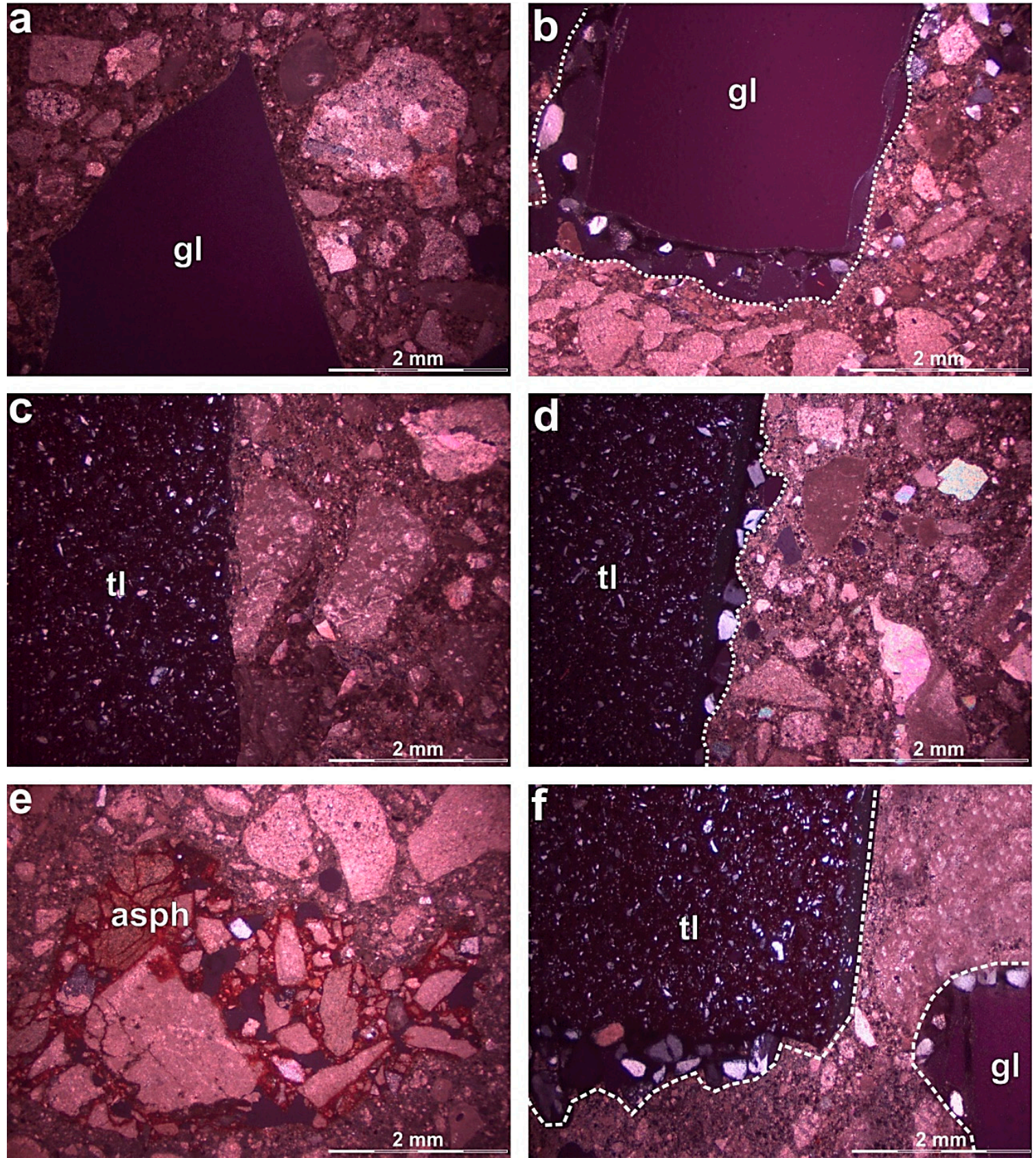

Figure 3. Photomicrographs of representative tested concretes in crossed nicols: (a) beer green glass as aggregate, (b) beer green glass with quartz primer as aggregate showing higher microroughness (c) tile as aggregate, (d) tile with primer as aggregate showing higher microroughness, (e) asphalt as aggregate, and (f) mix of beer green glass with quartz primer and tile with quartz primer as aggregates showing good cohesion with the cement paste. gl: glass, tl: tile, asph: asphalt. 

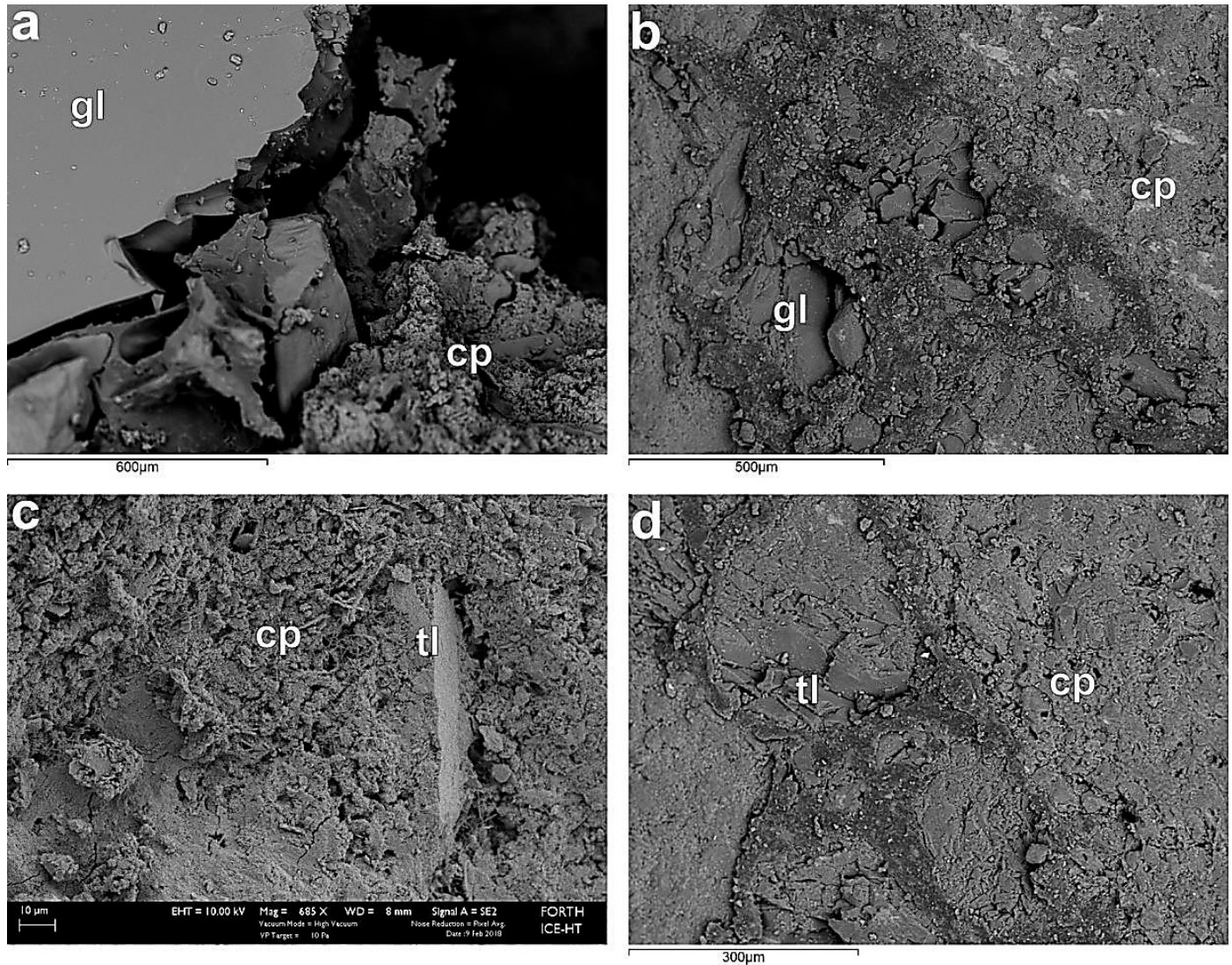

Figure 4. Back scattered electron images showing microstructures at the interface between cement paste and: (a) beer green glass; (b) beer green glass with quartz primer; (c) waste tile; and, (d) waste tile with quartz primer. gl: glass, $\mathrm{cp}$ : cement paste, tl: tile.

Concretes that were made by various mixtures of recycled materials used as aggregates were conducted. Among the various produced concrete specimens, those that are made by the mixture of glass coated with quartz primer (sample S6) in the smaller class and tile coated with quartz primer in other two classes, which is attributed to the highest concrete strengths. This is due to both the artificial increase of microroughness (due to their coating with quartz primer) and to the optimum interlocking of grains that has been created from the combination of glass coated with quartz primer in the small class tile coated with quartz primer in the bigger classes. Subsequently, concrete specimens that are made by mixture of tile coated with quartz primer in the bigger class and glass coated with quartz primer in the smaller classes attributed with lower but satisfactory strength, in contrast to sample S6. The lower strength is attributed to greater participation of glass that is coated with quartz primer in concrete specimens in contrast to sample S6. However, its satisfactory strength is due to the artificial increase of microroughness of the aggregate particles, as well as due to the good interlocking of grains. Concrete that is made by mixture of glass coated with quartz primer in the smaller class, of asphalt in the medium class, and tile coated with quartz primer in the bigger class presented lower strength, which is in contrast to other concretes that were made by mixtures of different recycled materials. This fact may happen due to the low strength of asphalt grains, combined with their impregnation in Fe-oxides. To sum up, the determinant factor seems to be the increase of the microroughness of the recycled materials which attributed to the optimum adhesion.

With the cement paste, as well as to the optimum bonding between the cement paste and the aggregate particles, and hence leading to the increase of the strength of the produced concretes. However, the highest concrete strength of sample S6 is attributed to both the artificial increase of the microroughness of the recycled materials used as concrete aggregates and the proportions of glass and tile in the respective grain sizes. Petrounias et al. $[56,63]$ petrographically studied natural materials, 
such as serpentinites and granodiorites, concluding in similar conclusions regarding the impact of microroughness on the concrete strength, the extended surfaces of serpentine contained are responsible for low microroughness similar to that of glass and tile, which negatively affect the concrete strength. The observations of the microroughness of the studied granodiorites, as they have been studied by Petrounias et al. [63], are similar to those of glass coated with quartz primer and of tile coated with quartz primer, leading in higher concrete strength values.

The artificial increase of microroughness after using quartz primer, although providing satisfactory results for the cohesion between the cement paste and the aggregate particle as for the satisfactory concrete strength values, cannot be realistic for future use as the quartz primer because of its high concentration of $\mathrm{SiO}_{2}$ may cause alkali-silica reactions in concrete specimens, as has been reported by Petrounias et al. [63], which noticeably limits their strength. An interesting proposal for further study could be the increase of the mechanical properties of the concrete by adding various types of fly ash in the used cement combined with the coating of the recycled materials that are used as aggregates with sandy primer without silica containing, which artificially increases their microroughness, and hence contributes to better bonding between them and the cement paste.

Using recycled materials, such as green beer glass, tile, and asphalt in concretes, presents significant impact on the economy by conserving raw materials and reusing energy cost, along with environmental benefits. Moreover, another benefit may be the creation of new job positions enhancing the general economy. To conclude, the recycling industry constitutes a much promising industry.

\section{Conclusions}

This study constitutes a petrographic and qualitative approach regarding how the artificially given microroughness of different recycled waste materials, when used as concrete aggregates, influences the mechanical strength of the produced concretes. The artificial increase of microroughness of the limited selected recycled materials used as aggregates, which was given after their coating with quartz primer, seems to be the determinant factor for the final concrete strength. The characteristics of quartz grains that are contained in the primer contribute to the good application of quartz primer on glass and tile aggregates. This good application, combined with the uniform distribution of quartz primer around the aggregates, is responsible for the increased strength values of the produced concretes, even though there was not significant variance among the UCS values. Concrete specimens that are produced by mixtures of glass aggregates coated with quartz primer and of tile aggregates coated with quartz primer the bigger size classes revealed the optimum cohesion between the cement paste and the aggregate particles among all of the tested concrete specimens. Additionally, the production of a new primer of similar characteristics to those of the used primer without $\mathrm{SiO}_{2}$ warrants further investigation in order to use this primer for coating the recycled materials that are used as aggregates in concrete.

Author Contributions: P.P. participated in the elaboration of laboratory tests, the interpretation of the results, coordinated the research and wrote the manuscript; P.P.G. participated in the elaboration of laboratory tests, the interpretation of the results and contributed to the manuscript writing; A.R. performed the SEM work and participated in the interpretation of the results; P.L. participated in the elaboration of laboratory tests; B.T. participated in the interpretation of the results; I.R. participated in the interpretation of the results and K.H. participated in the interpretation of the results.

Funding: This research received no external funding.

Acknowledgments: The authors wish to thank Drakopoulos of the Foundation for Research and Technology-Hellas (FORTH) Institute of Chemical Engineering and High Temperature Chemical Processes (ICE/HT) Rio-Patras, Greece and A.K Seferlis of the Laboratory of Electron Microscopy and Microanalysis, University of Patras for his assistance with the microanalyses and SEM micrographs.

Conflicts of Interest: The authors declare no conflict of interest. 


\section{References}

1. Jackson, N. Civil Engineering Materials; Macmillan Press Ltd.: London, UK, 1981.

2. US Concrete Industry Report; Library of Congress: New York, NY, USA, 2001.

3. Neville, A.M. Properties of Concrete, ELSB 5th Edition; Pearson Education Publishing Ltd.: London, UK, 2005.

4. Taylor, G.D. Materials in Construction, 2nd ed.; Longman Group Ltd., Longman House, Burnt Mill: Harlow, UK, 1994.

5. Rajput, R.K. Engineering Materials, 3rd ed.; S. Chard \& Company Ltd., Ram Nagar: New Delhi, India, 2006.

6. Neville, A.M. Properties of Concrete, 4th ed.; Pitman: London, UK, 1995.

7. Aulia, T.B.; Deutschmann, K. Effect of mechanical properties of aggregate on the ductility of high performance concrete. LACER 1999, 4, 133-147.

8. Thomas, M.D.A.; Folliard, K.J. Concrete aggregates and the durability of concrete. Durab. Concr. Cem. Compos. 2007, 247-281. [CrossRef]

9. Golewski, G.L. Improvement of fracture toughness of green concrete as a result of addition of coal fly ash. Characterization of fly ash microstructure. Mater. Character. 2017, 134, 335-346. [CrossRef]

10. Golewski, G.L. Generalized fracture toughness and compressive strength of sustainable concrete including low calcium fly ash. Materials 2017, 10, 1393. [CrossRef] [PubMed]

11. Golewski, G.L. An assessment of microcracks in the interfacial transition zone of durable concrete composites with fly additives. Compos. Struct. 2018, 200, 515-520. [CrossRef]

12. Ghahari, S.A.; Ghafari, E.; Lu, N. Effect of $\mathrm{ZnO}$ nanoparticles on thermoelectric properties of cement composite for waste heat harvesting. Constr. Build. Mater. 2017, 146, 755-763. [CrossRef]

13. Ghahari, S.A.; Ghafari, E.; Assi, L. Pore structure of cementitious material enhanced by graphitic nanomaterial: A critical review. Front. Struct. Civ. Eng. 2018, 12, 137-147. [CrossRef]

14. Ramezanianpour, A.A.; Esmaeili, M.; Ghahari, S.A.; Najafi, M.H. Laboratory study on the effect of polypropylene fiber on durability, and physical and mechanical characteristic of concrete for application in sleepers. Constr. Build. Mater. 2013, 44, 411-418. [CrossRef]

15. Mo, K.H.; Alengaram, U.J.; Jumaat, M.Z.; Yap, S.P.; Lee, S.C. Green concrete partially comprised of farming waste residues: A review. J. Clean. Prod. 2016, 117, 122-138. [CrossRef]

16. Soutsos, M.N.; Tang, K.; Millard, S.G. Concrete building blocks made with recycled demolition aggregate. Constr. Build. Mater. 2011, 25, 726-735. [CrossRef]

17. Blankendaal, T.; Schuur, P.; Voordijk, H. Reducing the environmental impact of concrete and asphalt: A scenario approach. J. Clean. Prod. 2014, 66, 27-36. [CrossRef]

18. Karade, S.R. Cement-bonded composites from lignocellulosic wastes. Constr. Build. Mater. 2010, 24, 1323-1330. [CrossRef]

19. Xuan, D.X.; Poon, C.S.; Zheng, W. Management and sustainable utilization of processing wastes from ready-mixed concrete plants in construction: A review. Resour. Conserv. Recycl. 2018, 136, 238-247. [CrossRef]

20. Medina, C.; De Rojas, M.S.; Frías, M. Reuse of sanitary ceramic wastes as coarse aggregate in eco-efficient concretes. Cem. Concr. Comp. 2012, 34, 48-54. [CrossRef]

21. Farzadnia, N.; Abang, A.A.A.; Demirboga, R.; Anwar, M.P. Effect of halloysite nanoclay on mechanical properties, thermal behavior and microstructure of cement mortars. Cem. Concr. Res. 2013, 48, 97-104. [CrossRef]

22. Kou, S.; Poon, C. A novel polymer concrete made with recycled glass aggregates, fly ash and metakaolin. Constr. Build. Mater. 2013, 41, 146-151. [CrossRef]

23. Ajmani, H.A.; Suleiman, F.; Abuzayed, I.; Tamini, A. Evaluation of concrete strength made with recycled aggregates. Buildings 2019, 9, 56. [CrossRef]

24. Castro, S.; Brito, J. Evaluation of the durability of concrete made with crushed glass aggregates. J. Clean. Prod. 2013, 41, 7-14. [CrossRef]

25. Tamanna, N.; Sutan, N.M.; Lee, D.T.C. Utilization of waste glass in concrete. In Proceedings of the 6th International Engineering Conference, Energy and Environment (ENCON 2013), Kuching, Sarawak, Malaysia, $2-4$ July 2013.

26. Abdallah, S.; Fan, M. Characteristics of concrete with waste glass as fine aggregate replacement. J. Eng. Technol. Res. 2014, 2, 11-17. 
27. Jani, W.; Hogland, W. Waste glass in the production of cement and concrete-A review. J. Environ. Chem. Eng. 2014, 2, 1767-1775. [CrossRef]

28. Meng, Y.; Ling, T.G.; Mo, K.H. Recycling of wastes for value-added applications in concrete blocks: An overview. Resour. Conserv. Recycl. 2018, 138, 298-312. [CrossRef]

29. Xiao, Z.; Ling, T.C.; Kou, S.C.; Wang, Q.Y.; Poon, G.S. Use of wastes derived from earthquakes for the production of concrete masonry partition wall blocks. Waste Manag. 2011, 31, 1859-1866. [CrossRef] [PubMed]

30. Xiao, Z.; Ling, T.C.; Poon, G.S.; Kou, S.C.; Wang, Q.Y. Properties of partition wall blocks prepared with high percentages of recycled clay brick after exposure to elevated temperatures. Constr. Build. Mater. 2013, 49, 56-61. [CrossRef]

31. Poon, C.S.; Chan, D. Paving blocks made with recycled concrete aggregate and crushed clay brick. Constr. Build. Mater. 2006, 20, 569-577. [CrossRef]

32. Ling, T.C.; Poon, C.S. Use of recycled CRT funnel glass as fine aggregate in dry-mixed concrete paving blocks. J. Clean. Prod. 2014, 68, 209-215. [CrossRef]

33. Ling, T.C.; Poon, C.S. Use of CRT funnel glass in concrete blocks prepared with different aggregate-to-cement ratios. Green Mater. 2014, 2, 43-51. [CrossRef]

34. Torkitrikul, P.; Chaipanich, A. Utilization of ceramic waste as fine aggregate in Portland cement and fly ash concretes. Cement Concrete Comp. 2010, 32, 440-449. [CrossRef]

35. Sadek, D.M.; Nothy, H.A.E. Properties of paving units incorporating crushed ceramic. HBRC J. 2014, 10, 198-205. [CrossRef]

36. Penteado, C.S.G.; Carvalho, E.V.D.; Lintz, R.C.C. Reusing ceramic tile polishing waste in paving block manufacturing. J. Clean. Prod. 2016, 112, 514-520. [CrossRef]

37. Vanitha, S.; Natrajan, V.; Prada, M. Utilization of waste plastics as a partial replacement of coarse aggregate in concrete blocks. Indian J. Sci. Technol. 2015, 8, 256-268. [CrossRef]

38. Sellakutty, D. Utilization of waste plastic in manufacturing of bricks and paver blocks. Int. J. Appl. Eng. Res. 2016, 11, 364-368.

39. Ohemeng, E.A.; Yalley, P.P.K.; Dadzie, J.; Djokoto, S.D. Utilization of waste low density polyethylene in high strengths concrete pavement blocks production. Civ. Environ. Res. 2014, 6, 2224-5790.

40. Park, S.B.; Lee, B.C.; Kim, J.H. Studies on mechanical properties of concrete containing waste glass aggregates. Cem. Concr. Res. 2004, 34, 2181-2189. [CrossRef]

41. Shaopeng, W.; Wenfeng, Y.; Yongjie, X. Preparation and Properties of Glass Asphalt Concrete; Key Laboratory for Silicate Materials Science and Engineering of Ministry of Education, Wuhan University of Technology: Wuhan, China, 2003.

42. Reindl, J. Reuse/Recycling of Glass Cullet for Non-Container Uses, Report by Recycling Manager; Dane County Department of Public Works: Sun Prairie, WI, USA, 2003; pp. 25-125.

43. Shayan, A.; Xu, A. Value-added utilisation of waste glass in concrete. Cem. Concr. Res. 2004, 34, 81-89. [CrossRef]

44. Byars, E.A.; Morales-Hernandez, B.; Zhu, H.Y. Waste glass as concrete aggregate and pozzolan. Concrete 2004, 38, 41-44.

45. Siddique, R.; Naik, T.R. Properties of concrete containing scrap-tire rubber-An overview. Waste Manag. 2004, 24, 563-569. [CrossRef] [PubMed]

46. Sagoe, K.; Brown, T.; Taylor, A. Guide Specification on Recycled Glass as Sand Replacement in Premix Concrete; CSIRO Building and Construction Engineering: Sidney, Australia, 2001; pp. 7-36.

47. Chen, Z.; Li, J.S.; Poon, C.S. Combined use of sewage sludge ash and recycled glass culler for the production of concrete blocks. J. Clean. Prod. 2018, 171, 1447-1459. [CrossRef]

48. Lam, C.S.; Poon, C.S.; Chan, D. Enhancing the performance of precast concrete blocks by incorporating waste glass-ASR consideration. Cem. Concr. Comp. 2007, 29, 616-625. [CrossRef]

49. Lee, G.; Ling, T.C.; Wong, Y.L.; Poon, C.S. Effects of crushed glass cullet sizes casting methods and pozzolanle materials on ASR of concrete blocks. Constr. Build. Mater. 2011, 25, 2611-2618. [CrossRef]

50. Hogland, W. Remediation of an old landfill site. ESRP 2002, 9, 49-54.

51. Medina, C.; Sánchez de Rojas, M.I.; Frías, M. Properties of recycled ceramic aggregate concretes: Water resistance. Cem. Concr. Comp. 2013, 40, 21-29. [CrossRef] 
52. Torgal, F.P.; Jalali, S. Compressive strength and durability properties of ceramic wastes based concrete. Mater. Struct. 2011, 44, 155-167. [CrossRef]

53. Al Bakri, A.; Mohd, M.; Norazin, M.N.; Kamarudin, H.; GheMohdRuzaidi, G. The potential of recycled ceramic waste as coarse aggregates for concrete. In Proceedings of the MUCET, Malaysian Universities Conferences on Engineering and Technology, Putra Brasmana, Perlis, Malaysia, 8-10 March 2008.

54. Wadie, E.H.; Sadek, E.F.; Abdel Wahad, M.M. The use of ceramic tile waste as aggregates in concrete. Int. J. Sci. Eng. Res. 2017, 8, 1461-1468.

55. Copola, L.; Kara, P.; Lorenzi, S. Concrete manufactured with crushed asphalt as partial replacement of natural aggregates. Mater. De Constr. 2016, 66, 324. [CrossRef]

56. Petrounias, P.; Giannakopoulou, P.P.; Rogkala, A.; Stamatis, P.M.; Tsikouras, B.; Papoulis, D.; Lampropoulou, P.; Hatzipanagiotou, K. The Influence of Alteration of Aggregates on the Quality of the Concrete: A Case Study from Serpentinites and Andesites from Central Macedonia (North Greece). Geosciences 2018, 8, 115. [CrossRef]

57. Part 1: Composition, Specifications and Conformity Criteria for Common Cements; EN 197-1; European Standard: Warsaw, Poland, 2011.

58. Methods for Sampling and Testing of Mineral Aggregates, Sands and Fillers, Part 1: Methods for Determination of Particle Size and Shape; BS 812; British Standard Institution: London, UK, 1975.

59. Standard for Selecting Proportions for Normal, Heavyweight and Mass Concrete; ACI-211.1-91; American Concrete Institute: Farmington Hills, MI, USA, 2002.

60. Part 3: Testing Hardened Concrete. Compressive Strength of Test Specimens; BS EN 12390; British Standard Institution: London, UK, 2009.

61. Standard Practice for Petrographic Examination of Hardened Concrete; ASTM C856; American Society for Testing and Materials: West Conshohocken, PA, USA, 2017.

62. Rigopoulos, I.; Tsikouras, B.; Pomonis, P.; Hatzipanagiotou, K. The influence of alteration on the engineering properties of dolerites: The example from the Pindos and Vourinos ophiolites (Northern Greece). Int. J. Rock Mech. Min. Sci. 2010, 47, 69-80. [CrossRef]

63. Petrounias, P.; Giannakopoulou, P.P.; Rogkala, A.; Stamatis, P.M.; Lampropoulou, P.; Tsikouras, B.; Hatzipanagiotou, K. The Effect of Petrographic Characteristics and Physico-Mechanical Properties of Aggregates on the Quality of Concrete. Minerals 2018, 8, 577. [CrossRef]

64. Concrete Technology Regulation; CTR-16; YPECHODE: Taipei, China, 2016. 